\title{
GERMAN INFOBAHN TRIALS FOR THE RESIDENTIAL CUSTOMER: TECHNOLOGICAL AND CONCEPTUAL ANALYSIS
}

\author{
Lutz Kolbe \\ Walter Brenner
}

\begin{abstract}
No other area of the upcoming Information Superhighway promises providers of technology and content as many business opportunities as Interactive Television (ITV). In Germany, one of the technologically most advanced countries in Europe with a high quality telecommunication network, six pilot projects are underway. Each has a different approach and varying participants, although all pilots are dominated by the Deutsche Telekom as network monopolist. These technology-driven trials lack an applicationoriented point of view which is necessary to explore the consumers' acceptance under real everyday conditions. In addition, the political funding based on the "multimedia" hype adds to the current uncertain situation. (C) 1997 Elsevier Science Ltd
\end{abstract}

Keywords - Interactive Television, residential information technology, home information systems, German telecommunications, Information Superhighway.

\section{INTRODUCTION}

In February 1995, the G-7 summit in Brussels discussed the issues of the Information Society and found it crucial to the further development of nations. The European Union issued materials such as the "Whitebook for Economic Growth" (Europaeische Kommission, 1993) or "Europe's Way to the Information Society" (European Commission, 1994) that have unanimously emphasized the relevance of research in information and communication technologies. The overall European production in the new electronic media exceeds US $\$ 350$ billion and is growing at an impressive $6 \%$ per annum (p.a.). Another study predicts two million new jobs in Germany, 10-11 million worldwide by the new millenium, thanks to multimedia-related industries. A steadily increasing share of Germany's Gross National Product (GNP) is already contributed by the media and communications sector (currently $10 \%$ ).

This article is based on a contribution to the Procedings of the Conference on Telecommunication and Information Markets (COTIM'95), 5-8 November 1995, Newport, Rhode Island, U.S.A. Address all correspondence to Lutz Kolbe or Walter Brenner, The Technical University of Freiberg, Faculty of Business Administration and Economics, Gustav-Zeuner-Str. 10, D-09596 Freiberg/Sachsen, Germany. 
Facing saturation in many market segments such as consumer electronics, the networking of private residences offers new business options for different market players. A 1994 Booz, Allen and Hamilton study for the German Parliament forecast an online market for private households of US $\$ 3.5$ billion for the year 2000 (Booz, Allen \& Hamilton, 1995). A more recent study forecasts 3-4 million digital TV households for the year 2000 spending about US $\$ 2.5$ billion for digital programming (or US $\$ 60$ each) (Landtag von Baden-Wuerttemberg, 1995). However, major obstacles have to be overcome. The technologies are in the introductory phase and the problems of reaching a "critical mass", quite typical for a new communication technology entering the market, still exist (Rogers, 1983, 1986; Weiber, 1992). Deutsche Telekom AG (henceforth DT), one of the world's biggest cable operators with 15 million households connected and a progressive 1.2 million fiber-to-the-home (optical access line, OPAL) supply in the rebuilt Eastern parts, has invited the industry to take part in six interactive television trials located in urban districts of Berlin, Hamburg, Stuttgart, Leipzig, Cologne/ Bonn and in the Nuremberg/Munich area (Deutsche Telekom, 1995; Deutschland startet..., 1994; Kulzer, 1995; Maassen, 1996). DT wants to test different technological approaches, such as hybrid fiber-coax or ordinary telephone lines, with various combinations of services to be offered to the residential market.

This article focuses on the analysis of German Infobahn trials. In the next section we give a critical description of the three most interesting trials in Stuttgart, Nuremberg and Berlin. The article then compares these three German pilots by pointing out their basic infrastructure, application types and content provision and summarizing their status and intention (see Table 1). Where appropriate, essential details from Time Warner Cable's 1993 Orlando Full Service Network (FSN) are excerpted as a supplement. The next section then analyzes the underlying managerial concepts and seeks lessons that can be learned from these trials. Finally, the future research issues of ITV trials in Germany are addressed.

\section{CRITICAL COMMENTS ON GERMAN ITV TRIALS}

Out of the six pilot projects in Germany we choose the three most heavily discussed in public, each of which has a distinctive characteristic in either technology, content or political background.

\section{Stuttgart trial}

The most cited trial in Germany is taking place in the city of Stuttgart and its suburbs (Autzen, 1995; Kulzer, 1994, 1995; Update, 1994). It is intensely supported by the Federal Government of Baden-Wuerttemberg (Wirtschaftsministerium, 1994; Hightext Verlag, 1996), of which Stuttgart is the state capital. Figure 1 gives an overview of the proposed concept.

The local government plans to establish Stuttgart as the leading multimedia area in Europe. However, this trial faces problems in many areas (Pitzer, 1995; Gestaltung..., 1994):

- DT was not successful in attracting the projected number of 4000 households to participate in the trial. Only about 2500 lead users have signed up to take part voluntarily. Consumer relunctance to participate in the trial has been underestimated. 
- Initially announced public funds have been cut and now the commitment of private investment must be higher than expected.

- Infrastructure providers are not able to agree on a common strategy. Some want to stress private household applications, others the business aspects. Several companies left the project but did join again after a redesign of the concept.

- Content providers, so far, have only declared their intent; they have not yet committed more fully to the trial. The infrastructure providers, mainly DT and Alcatel SEL (see Alcatel SEL, 1995), dominate the trial.

- Differences between DT and its trial allies about the usage of and access to the fiber-coax network are obvious. These partners suspect that DT simply wants to use its own networks to capacity instead of developing real new applications.

\section{Nuremberg trial}

The Nuremberg trial is driven by strong political support as well (Update, 1994). The Bavarian government regards the ITV trials as crucial. Public funding (about US \$35 million) has been promised and a holding company for the project, Multimedia Bayern $\mathrm{GmbH}$, has been founded (Stoiber..., 1995; Hightext Verlag, 1996). However, Nuremberg is facing competition from Munich (the capital of Bavaria and self-declared "Media City") which wants to start a trial for itself. At the moment it seems that the Federal Government does not know which city to prefer and where to invest the money. A distinctive feature of the Nuremberg trial is its two-fold architecture (Niemeier, 1995): 1000 households are connected via cable and 100 - so-called interactive households - via telephone lines running an asymmetric digital subscriber line (ADSL) capable of asymmetric interactive services (i.e. the bandwidth for the downstream is wider than for the upstream from the customer to the headend). This may be sufficient for services like Video-on-Demand with little interactivity (Dholakia, 1996); for fully symmetric services, however, like video communication, this protocol is not appropriate.

\section{Berlin trial}

The Berlin trial is the first operational ITV pilot in Germany. It is built as a demonstration showcase which should give first experience to DT in running such a nctwork. Besides the network from DT, Alcatel SEL functions as a system integrator. Of the 50 participants involved, only 20 are private households. Some interactive terminals have been placed in public places, for example, the $\mathrm{KaDeWe}$ (a famous department store in Berlin), and the focus is on point-of-information services. The film content consists of only a few movies for video-on-demand and some channels for which no bandwidth was allocated in the normal CATV network (Buecken, 1995; Alcatel SEL, 1995). Although the applied technology for the network employs fiber and coax, the backchannel is realized via conventional telephone lines and, accordingly, the intcractivity remains on a small scalc. Berlin has the advantage of reduced complexity and being the first trial to become operational.

\section{Orlando trial}

In international multimedia literature, we have come across many articles about the Orlando project (Maresca, 1995; Mediagruppe Muenchen, 1994; Ziemer, 1994; Schwartz, 1995). In all trade fairs Time Warner Cable, Silicon Graphics and their allies 


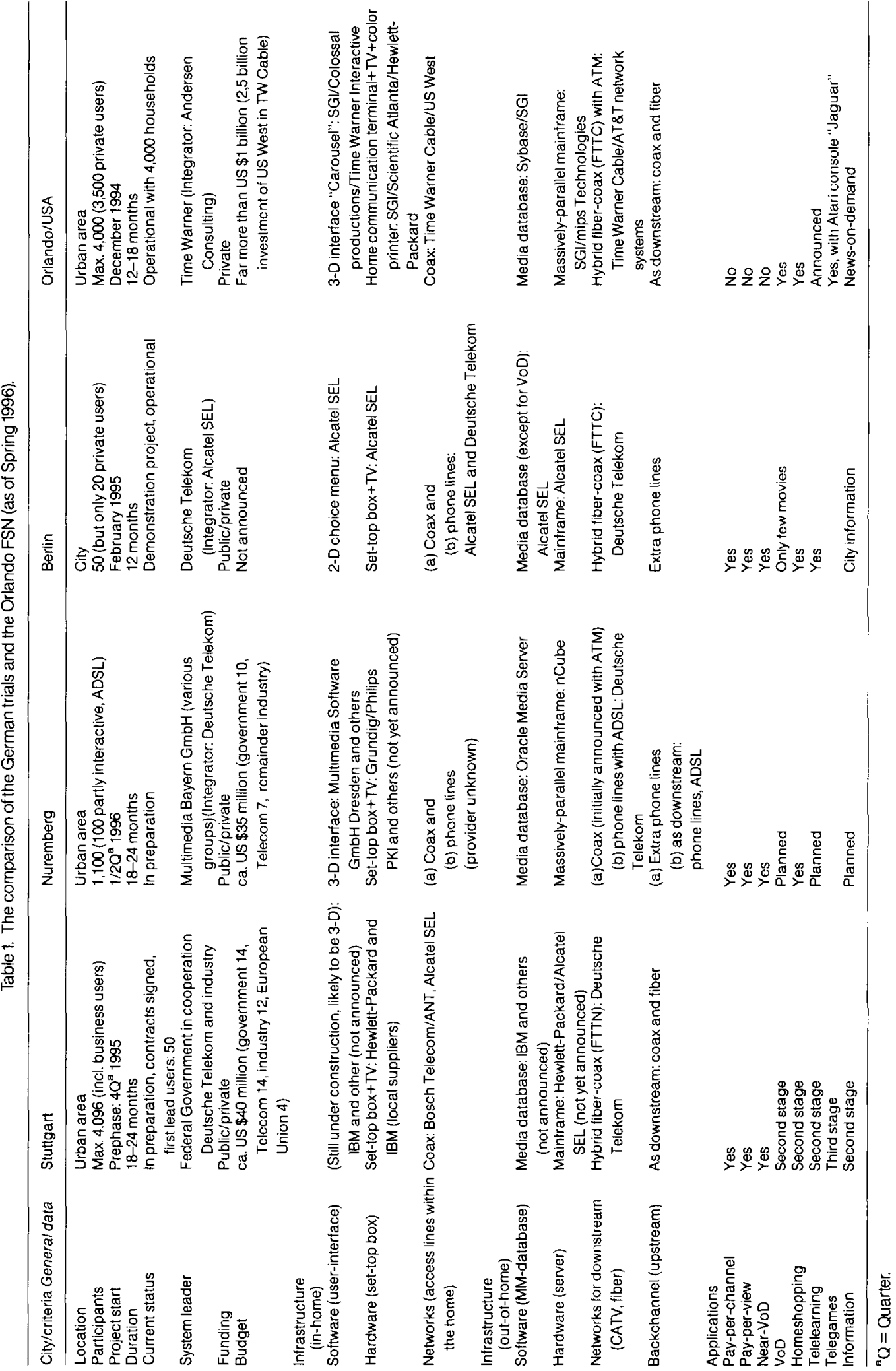




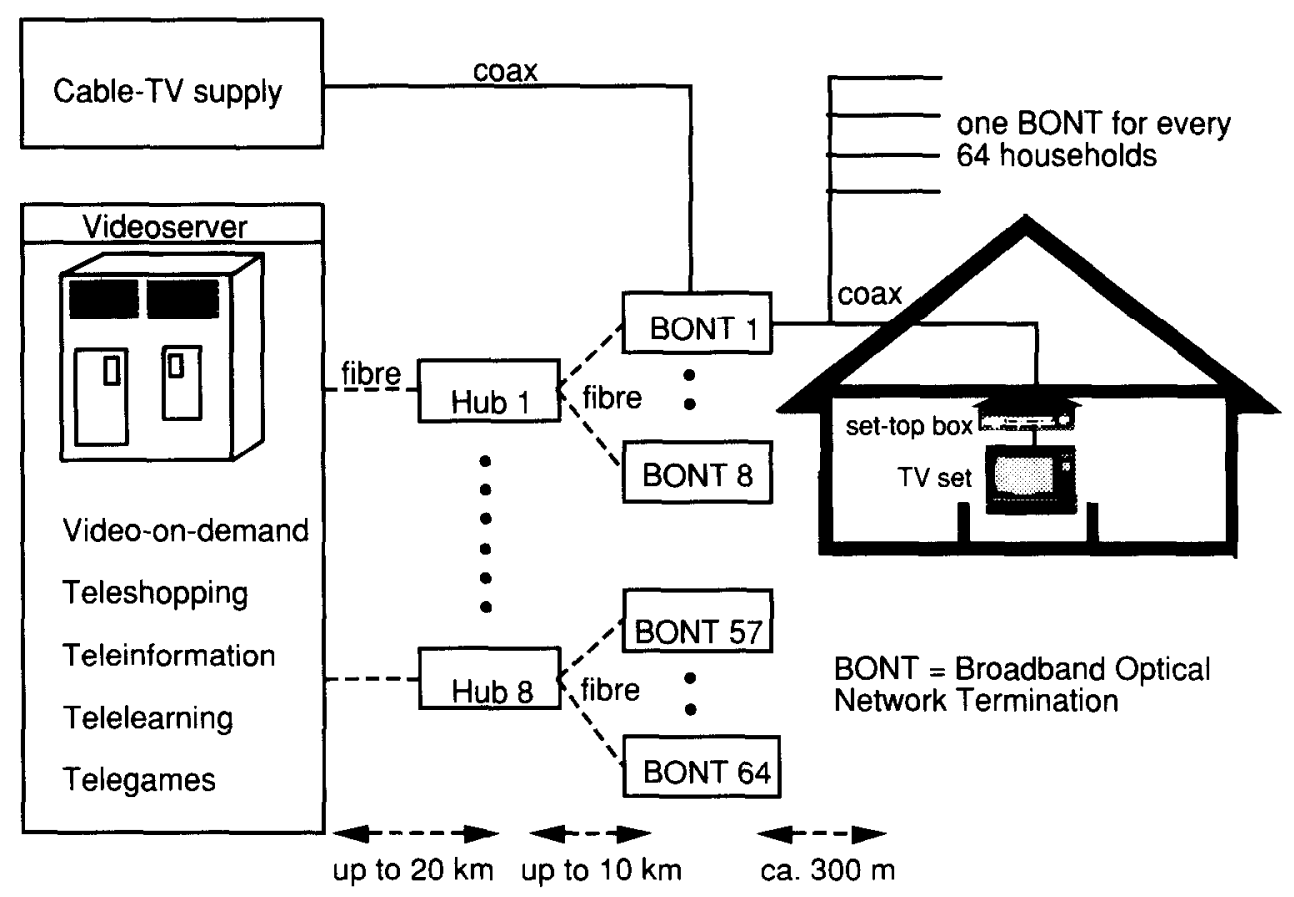

Figure 1. System concept of the Stuttgart trial (as of Spring 1996).

promote their progress towards their Orlando FSN by presentations and a series of press releases (Silicon Graphics, 1993; Time Warner Cable, 1993). Although the system was first announced in January 1993, two engineers of Time Warner and Silicon Graphics were the only "lead users" connected in October 1994 after a series of delays (Interactive, 1994). Then in December 1994, the Orlando network went "public" with five subscribers and, by summer 1995, 30 homes instead of 4,000 were "on-line". The projected number of 4,000 households was connected only in December 1995, a delay of 12 months. Furthermore, the long list of interactive applications has been shortened mainly to video-on-demand and home-shopping. All the technological problems with software and hardware equipment have forced many postponements. The complexity - in technology, in content and in coordinating the participating companies - has continued to be challenging. Nevertheless, the Orlando trial serves as a case study of the first baby steps firms must take into the multimedia age, even if they are megacompanies like Time Warner backed by a strategic alliance of renowned businesses (Steinbock, 1995).

\section{A COMPARISON OF TRIALS}

The trials of interactive TV (for details, see Ziemer, 1994) will be explored along the following dimensions (Brenner \& Kolbe, 1995): general data, technological infrastructure and applicational types. Other authors have defined the collection of information technology in the private home as "home information systems" and focused on the issues of marketing such products to the residential customer (Venkatesh \& Vitalari, 1986; Dholakia, Mundorf \& Dholakia, 1996) or on aspects of the novelty and variety of new, digital and interactive media (Pavlik, 1996). 
- In-home means all the soft-, hardware and networks inside the private premises. For example, a software component is the graphical user-interface like the "Carousel" of the Orlando FSN. The main in-home hardware devices are the television set and an attached set-top box. The networking inside the home encompasses the connection from the outer wall to the in-home outlet or hardware device itself.

- Out-of-home is the composition of soft, hardware and networks installed outside the home but necessary to run ITV. An example for software is the multimedia database, such as the Oracle MediaServer. On the hardware side, the video and customer administration server are noteworthy. The out-of-home networks consist of the fiber, coax or ordinary telephone lines provided by the telecommunication carrier or cable operator.

- Applications can be grouped into different main types (Brenner \& Kolbe, 1995): entertainment (including pay-per-channel, pay-per-view, near video-on-demand, (full) video-on-demand, telegames), transactional services (e.g. teleshopping), distance learning, information (tourist information or local news) and telemedicine. Business applications such as telework are of interest to certain trials as well.

The comprehensive collection of comparative data is shown in Table 1 . In the following discussion, we selectively address certain topics from Table 1 and highlight important facts. Because some of the contract negotiations have not been completed, changes are taking place almost every day and our discussion is constrained by this fluid environment.

\section{General data}

All trials are centered around an urban conglomerate. The maximum number of households range from 20 in Berlin to 4,096 (projected) in Stuttgart. The project start for Berlin was winter 1994/1995, the other trials planned the roll-out for spring/summer 1996, and they are still behind schedule. Except for the Berlin demonstration, all projects have a duration of up to two years. In all systems, DT as network monopolist plays the decisive role (Maassen, 1996). Facing the loss of their telecommunication monopoly in 1998 by European deregulation, DT seeks to gain a competitive advantage before any prospective private competitor can do so and while the comfortable financial basis of a monopolist is available (Steinfeld, Bauer \& Laurence, 1994). Though private investments are considerable in Nuremberg and Stuttgart, public funding and political backing remains pivotal for the trials (Landtag von BadenWuerttemberg, 1995). In contrast, the Orlando trial involves private network operators exclusively, like Time Warner Cable and U.S. West and the whole budget - more than 10 times as large as any of the German trials - consists of private funds.

\section{Infrastructures}

All ITV pilots showcase a specific technological approach. In principle, we can identify three different ways to bring downstream data to the home (Ziemer, 1994; Fuhrt, Kalra, Kitson, Rodriguez \& Wall, 1995):

- Telephone lines for up and downstream data using the ADSL protocol, as partly planned for Nuremberg.

- Hybrid fiber-coax in a fiber-to-the-neighborhood or -to-the-curb version, as in the Stuttgart, Berlin and Orlando trials. 
- Coaxial cable to the home as being tested in Nuremberg.

- The backchannel will be realized deploying these three different technologies:

(1) Via telephone lines using the ADSL protocol (partly Nuremberg for 100 households).

(2) External ordinary telephone lines (Berlin, Nuremberg for 1,000 households).

(3) The same way back as the downstream: hybrid fiber-coax cable (Stuttgart and Orlando).

DT is not sure about the premier technology for the future. Therefore, several distinct concepts are being evaluated in the trials. Even if the installed base favors the telephone system in the short run, future real time broadband applications will need more bandwidth to be fully interactive than ADSL can offer. Accordingly, most serious pilots use a hybrid fiber-coax approach where the backbone network deploys fiber, and the expensive, last mile to the home uses the coax lines.

All trial construction contracts have been placed with different providers of hardware and software in order to test their competence in running a real mass interactive multimedia information system. The objective is to figure out the appropriate technology as well as reliable providers for the different parts of the network.

- In-home sector: several different approaches are being tried. On the one hand, the in-home software part has been given to the domestic subsidiaries of IBM or Alcatel SEL; on the other hand, DT has started its own activities, for example, through the subsidiary "Multimedia Software GmbH Dresden" involved in the Nuremberg trial (Niemeier, 1995; Deutsche Telekom, 1996). Inside the home we usually find the broadband coax cable to the set-top box while in Berlin and Nuremberg phone lines have been used for the backchannel.

- Out-of-home sector: the multimedia databases are being provided by Oracle, IBM or Alcatel SEL. The tested huge massively-parallel video servers are produced by Hewlett-Packard (Stuttgart) or nCube (Nuremberg). DT provides their cable and telephone network along with the necessary enhancements: a hybrid fiber-to-theneighborhood network architecture in Stuttgart and Berlin, the cable network for Nuremberg (Niemeier, 1995) and, of course, the complementary telephone operations needed for Berlin and Nuremberg. Only Nuremberg has announced use of the advanced asynchronous transfer mode (ATM) as transfer protocol (Buecken, 1995). So far, however, cost and technology constraints seem to be forcing DT to abandon these plans.

\section{Applications}

Applications are as important for ITV trials as infrastructure. In Germany, hardly any content provider is strongly committed to the trials. They do not see any short term profits and thus are not interested in expensive experimental projects. This stems from their lack of experience in the multimedia business and the difficulties in making their content "digital" and "network-ready".

The six trials have promised different services. Stuttgart and Nuremberg will start with low level interactive applications in the broadcasting sector such as special interest channels and near video-on-demand (Wirtschaftsministerium, 1994). More interactive applications, for example, telegames, will be added in the future. In Stuttgart, a part of the pilot deals with business applications such as joint editing or video conferencing (Hightext Verlag, 1996). 
From the applicational point of view, the Berlin trial is an exception; as a result of the smaller complexity (merely 50 participants!), numerous services can be offered from special interest channels and near-video-on-demand to teleshopping and city information.

In Orlando, most services announced in press releases are still under construction or at the concept development stage due to setbacks in the basic technology. Video-ondemand, however, has been implemented ("Interactive...", 1994) on a small scale (100 movies available). The main business rationale is to examine the substitution potential of interactive services for conventional offers, for example, video-on-demand versus the US $\$ 14$ billion video rental market, or teleshopping versus catalog shopping sales of US $\$ 54$ billion or networked games versus traditional video games at US \$7.5 billion a year. At the time the trial was implemented, entertainment was seen as the driver for new information technologies (Jennings \& Love, 1996). Currently, complex services like medical monitoring and popular offerings like Internet access are to be introduced. Time Warner has released no data about the usage or economic feasibility because of the proprietary and strategic value of that information.

All trials have given high priority to technology, but little has been done to provide a set of applications appealing to the consumer. Being led by a consortia of infrastructure vendors has resulted in a reluctance among content providers to take part in such trials. In contrast to the infrastructure providers, the content providers are supposed to pay considerably for providing their content (Pitzer, 1995; Update, 1994) and yet their questions regarding return on investment have not been adequately addressed. In summary, the lack of "smart" content remains the weak point of all trials (Gestaltung..., 1994). The focus is on existing entertainment services supplemented by new forms of convenient access to movies such as special interest or pay-per-view programming (Steinbock, 1995). The list of really committed content providers is relatively short. Most of them have no financial commitment and are awaiting the projects to take shape. Trying to minimize their own risk, they hope that other competitors will take the first steps in order to react subsequently in accordance to the positive or negative result. The content providers do not seem to favor a pioneering strategy.

\section{Comparison: Orlando FSN versus German trials}

The concepts the Orlando pilot and the German trials have in common are:

- In-home infrastructure: intensive work on an intuitive, real-world object 3-D user-interface; in-home hardware is always TV-oriented plus set-top boxes (no PC-approach); within the home, usage of coax lines to the machine except for those that upload data via telephone lines.

- Out-of-home infrastructure: to keep wiring costs down and to enhance the likely demand, all trials are taking place in wealthy, densely populated urban or suburban areas; hybrid fiber-coax architecture seems to be the preferred system. Newly developed, enhanced multimedia-databases by traditional database vendors and (massively-parallel) mainframes as application and administration servers are being used. We find no PC-based network clusters in these trials.

- Applications and services: even though all the trials are located in affluent urban areas, the projected number of subscribers has not yet been reached. The focus is on entertainment applications, teleshopping and information-on-demand services; supply of content is not comprehensive and sufficient "full service" has not yet been reached. 
The main differences are:

- Only private funding is being used in Orlando while in Germany the sources are mixed and include public funds. Orlando's budget and number of allied partners involved are higher.

- A private network provider, Time Warner Cable, facing competition from other cable and telephone operators, conducts the trial in Orlando. In Germany, national telecom monopolist DT, in the process of being privatized, is the network owner and system leader. This dissimilarity is due to different market structures in the telecommunications industry and different maturity of regulatory environments.

- Orlando's network concept is technologically more advanced: it uses the highspeed fiber-based ATM-protocol. This has been announced, but will probably be not implemented, for the Nuremberg test. In Germany some trials evaluate the ordinary telephone for upstream data as a tentative solution.

\section{CONCEPTS UNDERLYING THE TRIALS}

Using the criteria applied in Table 1 this section examines why most of the trials share common characteristics and face similar problems. Table 2 provides a detailed description of the underlying concepts. Note that Table 2 states characteristics of the German trials exclusively and therefore generalizes to a German context only. Besides technological issues and insufficient support from content providers - as discussed above - four essential factors characterizing the scope of the German ITV trials can be extracted: installation costs, regulatory framework, telecommunications policy and consumer reluctance. These factors, stated in the first column of Table 2, are typical for the German interactive trials in general. The existing regulatory framework and national telecom policy in particular differentiate the German situation from the setting of the Orlando trial. The uncertainty regarding cost issues and return on investments, however, is a retarding factor for prospective investors all over the world.

- Costs: the investments required to enhance the existing cable or telephone plant exceed by far the projected returns in the short run (Pavlik, 1996). Initial cost estimates range from US $\$ 1,0003,000$ per household connected. A precise foundation for analysis of true incremental costs, however, does not exist (Pugh \& Boyer, 1995). Interactive broadband networks and components have turned out to be far more costly and technologically complex than initially expected. The speed of development in this area has not been as fast as predicted. Considerable technical hurdles have slowed down installation. However, less costly alternatives have emerged, notably through the Internet's World Wide Web. All but this last factor have accordingly increased the uncertainty of the ITV innovation process and caused hesitation among participating partners.

- Regulatory framework: the German telecommunications market is in transition to a deregulated, competitive market in 1998. Yet for the duration of the trials, DT will be fully in control of residential cable and telephone communications (Steinfeld et al., 1994). In 1992, for instance, Germany's telecommunication equipment accounted for US $\$ 13$ billion, of which a remarkable $90 \%$ was purchased by DT. This has a decisive impact on the design (i.e. technology focus) and leadership of the trials. 
Telecommunications policy: in Germany, telecommunications have always been conceived as a national task initiated by public authorities and discussed by numerous societal groups. This also applies to the trials: steering committees, project task forces and especially the funding consist of both private and public stakeholders.

IT reluctance of German users: unlike the American households, German consumers are more cautious about new technologies entering their private sphere (Mundorf, Dholakia, Dholakia \& Westin, 1996; Mundorf, Meyer, Schulze \& Zoche, 1994); for example, the penetration of home PCs and network connectivity are as little as half the American level. Due to this cultural difference, the German approach to ITV trials is supposed to be built on experiences from abroad, but also to follow its own unique path. All technological features such as user-interface or response time to requests have to assume a voluntary, occasional and inexperienced user (for details of technology in German households, see Meyer $\&$ Schulze, 1993). Consumer willingness to increase the share of their household budget allocated to electronic entertainment and information is questionable. Video-on-demand, for instance, was thought to be a "killer application", saving consumers the trip to the video store and the disappointment of not finding the movie they want (Dholakia, 1996). Evidence suggests that although this convenience is desirable, consumers are unlikely to pay a significant surcharge for this privilege (Mundorf, 1996).

\section{FUTURE OUTLOOK}

\section{Context issues}

In Germany, the telecommunication situation is very different from that in the United States. DT has a monopoly in the cable and telephone business. Everybody has to use its telecommunication trunks for residential communication. A number of private organizations, mainly from the electric utility business such as RWE (with its subsidiary RWE Telliance) are preparing for competition in 1998 when European law forces Germany to liberate the telecommunication market (Hightext Verlag, 1996). However, for a long time in the future, the DT as a "de facto-monopolist" will continue to be the only supplier of a widespread network. Only the emerging digital direct-to-the-home broadcast satellite (DBS) service is likely to become a threatening competitor within the video entertainment because it bypasses the DT network.

The national law for broadcasting is not prepared for interactive digital services. It prohibits, for instance, the distribution of a full time shopping channel (Visionen..., 1995). If an individual video stream is no longer deemed to be broadcasting, the issue of control over content arises. Despite the multimedia enthusiasm of some politicians (Wirtschaftsministerium, 1994; Stoiber..., 1995) the German legislative situation is ambiguous because of a fear of social divergence among the "information rich" and the "information poor". Since telecommunications in Germany is on the edge of change, precise predictions for the future ITV market are nearly impossible and many projections for the future must be looked upon with caution.

\section{Research issues}

All trials promised to explore the consumers' attitude towards the new interactive features of TV and the feasibility of the new technology. Yet up to now only limited 
Table 2. Conceptual analysis of German ITV trials.

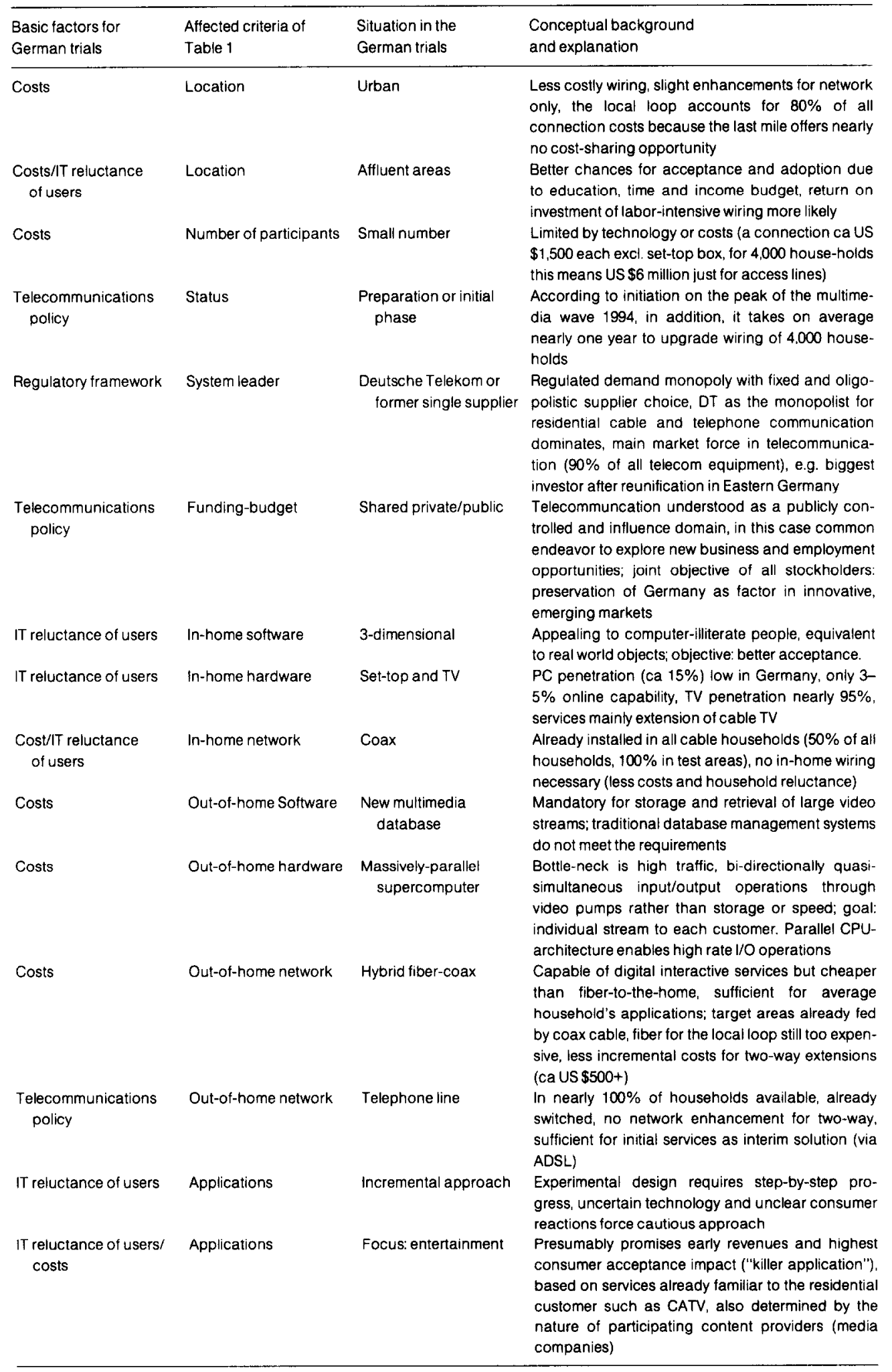


results with limited validity are available. Announced to work with thousands of subscribers, only a handful actually take part. This is mainly due to technological problems and an explosion of costs but political opportunism exploiting the current multimedia hype is also responsible for the delays (Landtag von Baden-Wuerttemberg, 1995). Politicians have chosen the "wonderful new ITV world" for their own purposes, but have failed to back it with real financial and expert support. The time and money budget constraints of the private household make interactive television compete with a variety of different media. In addition, some observers suggest that the traditional TV viewer does not want to be interactive at all (Kulzer, 1995). Although there are numerous publications about the German trials, the depth and content of the information remain fairly superficial. The same applies to the much-heralded Orlando trial. Future research has to answer questions regarding the kind of services the residential customer actually needs, wants and accepts and, last but not least, the amount of disposable time and income he or she is eventually willing to spend on ITV.

\section{REFERENCES}

Alcatel SEL (Ed.) (1995). Opening of the Deutsche Telekom Pilot "Interactive Video Services Berlin". Press release, Stuttgart, (March).

Autzen, H. (1995)Aufbruch in die interaktive Medien-Zukunft. Elektronik, 5, 50-58.

Booz, Allen \& Hamilton. Zukunft Multimedia. IMK: Frankfurt am Main.

Brenner, W., \& Kolbe, L. (1995) Computerized Information Processing in the Private Household: First Outlook on Business Impacts. Telematics and Informatics, 12(2), 97-110.

Buecken, R. (1995)Hauptstadt im Multimedia-Glanz. vdi Nachrichten, 9, 5.

Deutsche Telekom (Ed.) (1996). Multimedia Software GmbH Dresden. WorldWideWeb site, (http:// www.DTAG.de/mms-dresden).

Deutsche Telekom Generaldirektion (Ed.) (1995). Kabelanschluss. Die Zukunft des Fernsehens. Jetzt auf CD-ROM. CD-ROM, Bonn.

Deutschland startet in die interaktive Fernsehzukunft (1994). multiMEDIA Telegramm, (12 September), 5-6.

Dholakia, R. R. (1996). Taking Movies-on-Demand to Market. In R. R. Dholakia, N. Mundorf \& N. Dholakia (Eds), New Infotainment Technologies in the home. Lawrence Erlbaum Associates, 75-88.

Dholakia, R. R., Mundorf, N. \& Dholakia, N. (1996). Bringing Infotainment Home: Challenges and Choices. In R. R. Dholakia, N. Mundorf \& N. Dholakia (Eds), New Infotainment Technologies in the home. Lawrence Erlbaum Associates, 1-20.

Europaeische Kommission (Ed.) (1993). Whitebook “Wachstum, Wettbewerbsfaehigkeit, Beschaeftigung”, Brussels.

European Commission (Ed.) (1994). Europe's way to the Information Society An action plan. Communication to the Council and the European Parliament, Brussels, (19 July).

Eckstein, E. (1994). Datenhighway wird Realitaet. Pablo, 10, 30-32.

Furht, B., Kalra, D., Kitson, F. L., Rodriguez, A. A., \& Wall, W. E. (1995). Design Issues for Interactive Television Systems. IEEE Computer, 5, 25-39.

Gestaltung von Anwendungen im Pilotprojekt multimediale Dienste in Baden-Wuerttemberg (1994). Round table discussion at the University of Hohenheim, Stuttgart.

Hightext Verlag (Ed.) (1996). Pilotprojekte Interaktives Fernsehen in Deutschland. World-Wide Web site, (http://www.hightext.cube.net/itv.htm).

Interactive Future won't be rushed in Orlando (1994). Consumer Information Appliance, 5, 14-17.

Jennings, B. \& Love, C. (1996). Entertainment as the driver of ncw information technology. In R. R. Dholakia, N. Mundorf \& N. Dholakia (Eds), New Infotainment Technologies in the Home. Lawrence Erlbaum Ass.

Kulzer, R. (1994). Viele Tests fuer Zukunfts-TV. Handelsblatt, 217, 14.

Kulzer, R. (1995). Interaktives Fernsehen in Deutschland - Digitaler Spatenstich. Pablo, 16-18.

Landtag von Baden-Wuerttemberg (Ed.) (1995). Bericht und Empfehlungen der Enquete-Kommission Entwicklung, Chancen und Auswirkungen neuer Informations- und Kommunikationstechnologien in Baden-Wuerttemberg. 11. Wahlperiode, Drucksache 11/6400.

Maassen, N. (1996). Deutsche Telekom's network platform for interactive video services. In W. Brenner \& L. Kolbe (Eds), The Information Superhighway and Private Households - Case Studies of Business Impacts. Physica: Heidelberg, 1996, 75-84.

Maresca, T. (1995). Cable Companies take it slow with ITV. Consumer Information Appliance, 6, 17-19.

Mediagruppe Muenchen (MGM) (Ed.) (1994). Marktuebersicht Interaktives Fernsehen. Market Study, Munich, 52-58. 
Meyer S. \& Schulze, E. (1993). Technisiertes Familienleben: Blick zurueck und nach vorn. Berlin: Edition Sigma.

Mundorf, N. (1996). Information technologies in the home: policies and markets. In W. Brenner \& L. Kolbe, (Eds), The Information Superhighway and Private Households - Case Studies of Business Impacts. Heidelberg: Physica, 1996, 384-397.

Mundorf, N., Dholakia, R. R., Dholakia, N., \& Westin, S. (1996). German and American Consumer Orientations to Information Technologies: Implications for Marketing and Public Policy. Journal of International Consumer Marketing, 8(3/4), 125-143.

Mundorf, N., Meyer, S., Schulze, E., \& Zoche, P. (1994). Families, information technologies, and the quality of life: German research findings. Telematics and Informatics, 137-146.

Niemeier, J. (1995). Interactive TV pilots in Germany. Personal Conversation, Freiberg.

Pavlik, J. V. (1996). New Media Technology: cultural and commercial perspectives. Allyn and Bacon: Needham Heights.

Pitzer, S. (1995). Die einst hochfliegenden Traeume sind vom Absturz bedroht. Frankfurter Rundschau.

Pugh, W., \& Boyer, G. (1995). Broadband Access: Comparing Alternatives. IEEE Communications, 8, 3446.

Rogers, E. M. (1983). Diffusion of Innovations. New York-London, 3rd edition.

Rogers, E. M. (1986). Communication Technology, The new media society. New York.

Schwartz, E. I. (1995). People are supposed to pay for this stuff? Wired, 3(7), 148-153, 187, 190191.

Silicon Graphics (Ed.) (1993). Time Warner selects Silicon Graphics to develop key technologies for interactive digital cable TV. Press release, (June 7).

Steinbock, D. (1995). Triumph and Erosion in the American Media and Entertainment Industries. Westport, CT: Quorum Books.

Steinfeld, C., Bauer, J. M. \& Laurence, C. (Ed.) (1994). Telecommunications in Transition. Thousands Oaks: Sage.

Stoiber gruendet Multimedia Bayern GmbH (1995). multiMEDIA Telegramm, 1.

Time Warner Cable (Ed.) (1993). The Full Service Network. Press release.

Update (1994). TV interaktiv - Hintergrunddienst ueber interaktives Fernsehen, 2, 2-11.

Venkatesh, A., \& Vitalari, N. (1986). Computing technology for the home: Product strategies for the next generation. Journal of Product Innovation and Management, 3, 171-186.

Visionen vom Kaufhaus im Wohnzimmer, (1995). Hannoversche Allgemeine Zeitung. 100, 13.

Weiber, R. (1992). Diffusion von Telekommunikation. Wiesbaden: Gabler.

Wirtschaftsministerium Baden-Wuerttemberg (Ed.) (1994). Spoeri legt Testgebiete fuer europaweit einmaligen Grossversuch im Grossraum Stuttgart fest. Press release 188, (August).

Ziemer, A. (1994). Digitales Fernsehen. Heidelberg: R. v. Decker.

Acknowledgement-The authors thank Prof. Dr Ruby Roy Dholakia and Prof. Dr Norbert Mundorf for their comments on the revision. Insights that led to this article were gained by Lutz Kolbe being a visiting research scholar at the University of Rhode Island, Research Institute for Telecommunications and Information Marketing (RITIM), Kingston/USA. The author acknowledges the Leisler Kiep-Foundation and RITIM for supporting his research. 